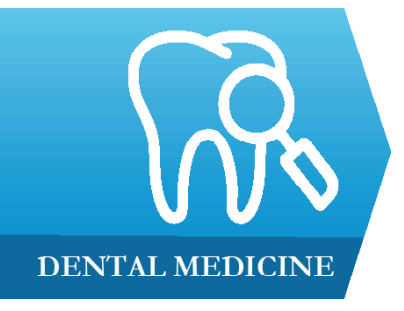

DENTAL MEDICINE

\title{
Principles of biomechanics in oral implantology
}

Avram Manea ${ }^{1}$, Simion Bran ${ }^{2}$, Cristian Dinu ${ }^{1}$, Horatiu Rotaru ${ }^{1}$, Ioan Barbur ${ }^{2}$, Bogdan Crisan ${ }^{2}$, Gabriel Armencea ${ }^{1}$, Florin Onisor ${ }^{1}$, Madalina Lazar ${ }^{1}$, Daniel Ostas ${ }^{2}$, Mihaela Baciut ${ }^{2}$, Sergiu Vacaras ${ }^{1}$, Ileana Mitre ${ }^{1}$, Liana Crisan ${ }^{2}$, Ovidiu Muresan ${ }^{1}$, Rares Roman ${ }^{1}$, Grigore Baciut ${ }^{1}$

1) Maxillo-Facial Surgery and Radiology Department, Iuliu Hatieganu University of Medicine and Pharmacy, Cluj-Napoca, Romania

2) Oral Rehabilitation Department, Iuliu Hatieganu University of Medicine and Pharmacy, Cluj-Napoca, Romania
DOI: $10.15386 / \mathrm{mpr}-1512$

Manuscript received: 05.07.2019 Accepted: 02.09.2019

Address for correspondence: dr_brans@yahoo.com

\begin{abstract}
Background and aims. The principles of biomechanics comprise all the interactions between the body (tissues) and the forces acting upon it (directly or via different medical devices). Besides the mechanical aspects, the tissues response is also studied. Understanding and applying these principles is vital for the researchers in the field of oral implantology, but they must be equally known by the practitioners. From the planning stages to the final prosthetic restoration, they are involved in each and every aspect. Ignoring them inevitably leads to failure.

Methods. The first part of this paper includes a review of our current research in oral implantology (mechanical, digital and biological testing), while the second part includes a review of the available literature on certain biomechanical aspects and their implications in everyday practice.

Results. Our research opens new study directions and provides increased chances of success for dental implant therapy. The practical aspects of our findings, combined with the available literature (from the basic principles described more than 40 years ago to the most recent studies and technologies) can serve as a guide to practitioners for increasing their success rate.

Conclusion. While no therapy is without failure risk, a good understanding of the biomechanics involved in oral implantology can lead to higher success rates in implant supported prosthetic restorations.
\end{abstract}

Keywords: oral implantology, biomechanics, bone augmentation

\section{Background and aims}

According to the general definition, biomechanics is defined as mechanics applied to biology, while mechanics itself comes as a response of the bodies to forces or displacements. Other sources describe biomechanics as the study of the structure, function and motion of the biological systems. These observations can be made ranging from cell organelles to the entire organism.

Oral implantology has become an independent branch of Dentistry decades ago but it still maintains a close touch with all the other branches. Implant therapy should always be considered from numerous points of view, including anatomy, maxillofacial surgery, periodontology, prosthetic dentistry, dental and facial esthetics, and finally, biomechanics.

The present paper describes our experience in the field of oral implantology (implant development and testing) and presents the conclusions drawn so far in relation with the biomechanical aspects that can help practitioners in everyday dental work. Also, the recent studies on the subject are reviewed in order to compare our conclusions.

The first studies describing current implant designs and techniques, belong to P. Brånemark and date from the 1950's to the 1970's. He was also the first to describe the concept of "osseointegration" which became similar to success in oral implantology [1]. In parallel with all the studies regarding implant form 
and function, he also focused on the mechanic principles and their application in the field, realizing that they cannot be separated [2]. In oral implantology, the biomechanical aspects refer primarily to the loads applied on the implant directly or via the prosthetic restoration more frequently, mostly during mastication (the main source of load in the oral cavity). The stress that is transferred by the implant to the surrounding bone is also of critical importance as is the response of the bone (forces and histological adaptations). Many authors claim that the success or failure of implant therapy is closely related to the correct understanding of the biomechanical principles involved [3].

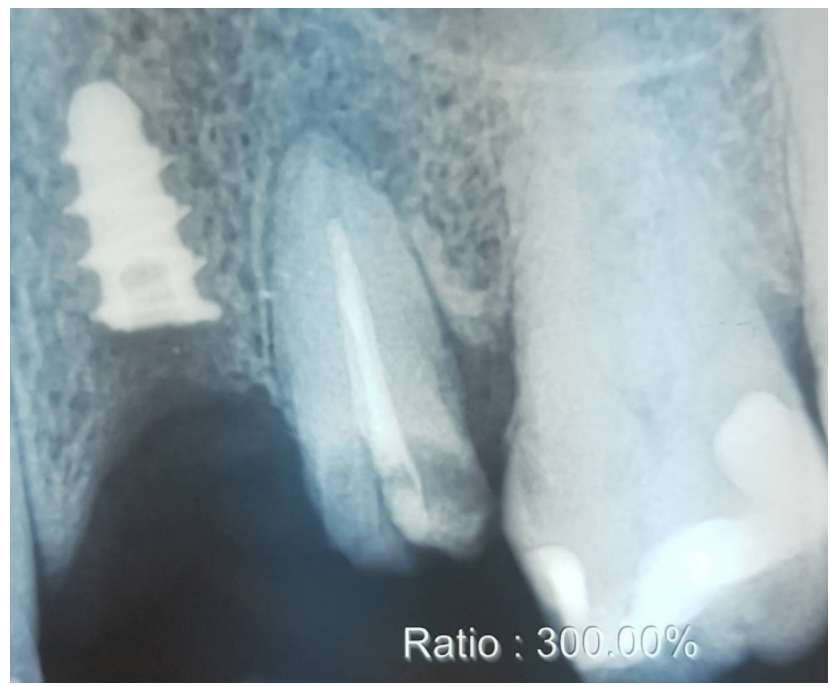

Figure 1. Implant fracture after a few years of function. The implant was part of a mixed support prosthetic restoration (implant and natural tooth).

The forces encountered in the oral cavity during physiological function have a wide range and must be well known when designing and in vitro testing of dental implants. Non physiological forces also appear in most patients, with much higher intensities than the former, which must also be taken into consideration, in order to avoid implant failure. For instance, in the molar region, vertical forces between 380 and $880 \mathrm{~N}$ can be developed, while in the incisor area, they are considerably lower $(220 \mathrm{~N}$ or less). Lateral forces, in normal conditions (correct tooth position, no dental-maxillary anomalies, no parafunctions etc.) are around $20 \mathrm{~N}$, depending on the morphology of the occlusal surface of the tooth and the tooth angulation [4]. In dental implants, depending on their position and prosthetic restoration, lateral loads can exceed 200 or $300 \mathrm{~N}$ [5]. While vertical (compression) forces are well tolerated by the implant, lateral (shear) forces can lead to implant failure in a short amount of time (Figure 1).

Mechanical failure of the implant can be caused by several factors. That is why any new dental implant must undergo a serious in vitro testing phase before entering production. ISO 14801 (Dynamic loading test for endosseous dental implants) is currently the accepted standard for these tests, although it has severe limitations [6]. More and more authors suggest using Fine Element Analysis (FEA) as a substitute or in conjunction with the classical means of testing, as it can provide supplemental information and reduce testing time and costs $[7,8]$. Even the best results in laboratory testing and FEA cannot guarantee clinical success, if the basic biomechanical principles are not taken into consideration during insertion and loading. The leading cause of dental implant loss is considered to be of biological nature but mechanical complications (implant fracture, abutment screw fracture, and abutment fracture) are almost as important $[9,10]$. Failure can also come from an incorrect prosthetic plan (no metal framework in OD, Cantilever $>15 \mathrm{~mm}$, extreme length of the reconstruction, splinting teeth and implants, ignoring the patient's anatomy and function (Figure 2) etc.) [11,12].

The most frequently taken into account local parameters concerning the implant are related to diameter, length and angulation, dictated by the bone anatomy. Also, the implant design is taken into consideration, especially when evaluating the bone quality (density) $[9,12]$. Practitioners are also increasingly aware of the implant surface treatment, with a considerable effect on osseointegration and function [13].

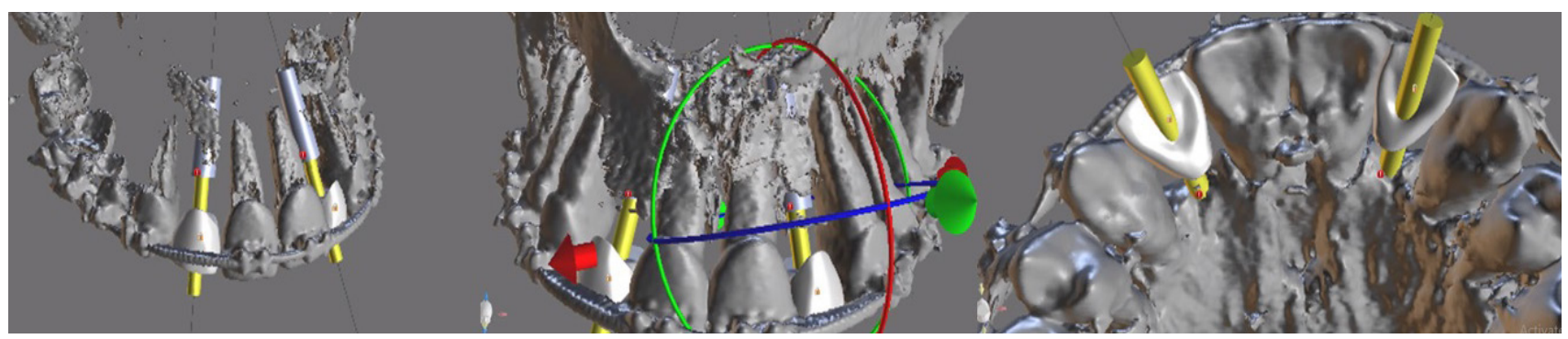

Figure 2. Simulation of implant placement in extreme skeletal (sagittal and transversal) discrepancy. Patient did not wish to undergo orthognathic surgery. 


\section{Methods}

Our first studies begun more than eight years ago, from the premises that dental implant survival can be improved by lowering the stress on the surrounding bone. For this purpose, we designed and produced a new type of dental implant (Figure 3) with a shock absorbing mechanism and 3D tooth like mobility. Since the implant must present primary and secondary stability provided by the correct osseointegration, the previously mentioned mobility can only come from inside the implant. We conducted several studies (mechanical testing, fatigue testing according to ISO 14801, FEA etc.) which lead to obtaining a functional prototype. While the first produced implants had a 10.000 to 35.000 test cycle life according to ISO 14801, through several design improvements, the current implant model manages to easily reach the 5 million mark. In vivo tests will soon follow. During these tests and redesigns, we also discovered several relevant biomechanical aspects that can be very helpful for everyday practice regarding implant rotation and insertion.

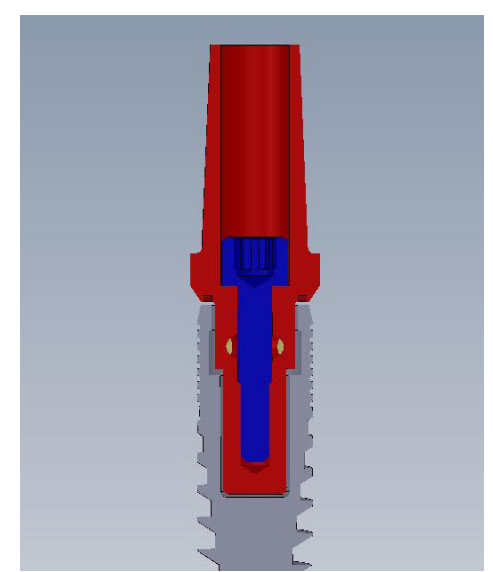

Figure 3. Original dental implant design.

Other studies that we conducted in the past years are related to porous dental implants. Such structures present numerous advantages, such as better osseointegration, increased bone to implant contact, reduced elastic modulus which translates into less harmful forces applied onto the bone, they provide a carrier for different substances etc. Yet, they present some potential inconveniences, from a biological and especially biomechanical point of view. Their cavernous structure might provide a better protection for microorganisms during sterilization and, depending on the percentage of porosity, might lead to unsatisfactory mechanical properties. The biological studies that we conducted so far show promising results, while mechanical tests are still in progress.

Several parameters which are known to be of crucial importance for decades in oral implantology and also proved very relevant from a biomechanical point of view throughout all our studies were followed in a systematic review in April-May 2019 on PubMed, taking into consideration only studies that were more recent than 2014 and which also mentioned the practical implications of such parameters. Implant dimensions (length and diameter), bone to implant contact, crown/implant ratio, cantilevers, vectors and primary stability were followed.

\section{Results}

The search on PubMed following the terms: "dental implant length diameter" showed 5375 results, out of which 3342 were published in the last 5 years. A total of 13 studies were selected based on the inclusion criteria, out of which 6 were performed using Fine Element Analysis, 3 Photoelastic Analysis, 2 clinical studies, 1 micro CT and 1 Resonance Frequency Analysis. All the studies reported decreased stress at implant or surrounding bone level when increasing the length and diameter of the implant.

The search in the same database for: "dental implant cantilever" showed 345 results, with 110 over the past 5 years. A total of 15 studies were included in our review based on the previously mentioned criteria. FEA was used in 6 studies, Photoelastic Analysis in 2, 2 clinical studies and 5 reviews were also included. The common conclusion was that cantilevers, although being a frequent and useful treatment option, must be used with caution.

When searching for the words "crown implant ratio", PubMed showed 215 results, with a total of 109 over the past 5 years. Sixteen studies were included in our review, out of which 9 were clinical studies, 3 were performed by using FEA, 3 reviews and 1 was performed by Photoelastic Analysis. The results were inconstant, some of them showing significant differences between success rates of prosthetic restorations depending on the crown to implant ratio, while some mentioning similar success rates, irrelevant of this ratio.

\section{Discussion}

The results of our previous studies and those found by performing a review of the latest articles on the topic restate the crucial importance of understanding and applying the biomechanics principles in oral implantology. Although the testing methods evolved during the past years (increased number of digital simulations), the findings are similar with the information obtained via classical in vitro and in vivo testing obtained over the previous decades. Digital testing, especially FEA, proves very valuable in testing medical devices but, in our experience and in the available literature, caution when interpreting the findings of FEA for simulations involving tissues is advised. In order to obtain relevant results, all materials parameters should be perfectly defined. While this is possible with inert materials such as titanium (or titanium based alloys 
- frequently used for dental implants), defining tissue parameters for FEA is impossible. Approximations can be made, based on population values, but the exact tissue response cannot be calculated, making this testing method only partially relevant when live tissues are involved.

The implant size (diameter, length) remains the main selection criteria when it comes to developing the treatment plan, mostly based on the available alveolar bone. Unfortunately, due to severe atrophies, narrower or shorter implants than optimal can be used. In such cases, bone augmentation used to be the "golden standard". At present, opinions regarding such procedures are divided amongst specialists. Narrow implants were considered totally inappropriate for the lateral regions where the forces are much higher compared to the frontal region. Still, recent studies suggest that if all other parameters are favorable, narrow implants can be considered as a treatment option, even for the molar area $[14,15]$. Other studies enter into more detail, defining the term of "narrow implant" by assigning exact values. For instance, Schiegnitz and AlNawas divide them into 3 categories in their meta-analysis (I $<3$, II 3-3.25, III 3.25-3.5 mm). They conclude that the real issues arise only with the first category, while the last two show similar results as the standard diameter implants [16]. Extra short $(<7 \mathrm{~mm})$ and extra narrow $(<3.5 \mathrm{~mm})$ implants present increased failure rates in comparison with standard implants according to the meta-analysis conducted by Pommer in 2018 [17]. FEA suggests that increasing the implant length the stress is reduced in the cancellous bone, while by increasing the implant diameter the stress decreases as cortical bone level $[18,19,20]$. As mentioned before, these results must be interpreted with caution, since FEA cannot accurately predict the tissue response and adaptation mechanisms. Other studies suggest that different implant lengths are not relevant when evaluating the stress transmitted to the surrounding bone, if axial forces are applied [21,22]. The increased implant length translates into increased insertion torque value, higher Periotest values and theoretically significantly affected bone-to-implant contact (BIC) area. Yet, a comparison between a $8.5 \mathrm{~mm}$ implant and a $13 \mathrm{~mm}$ implant $(52.9 \%$ increase) only generates a $38.2 \%$ increase in BIC (67.97 $\mathrm{mm}^{2}->94.16 \mathrm{~mm}^{2}$ ). This is why the efforts of augmenting the alveolar ridge may not be always justified.

These differences in opinion suggest that more studies on this topic are welcome. Although standard or wide implants with increased lengths are considered optimal, in severe atrophy cases, one should thoroughly evaluate the opportunity of augmenting the bone versus using narrow or short implants. The disadvantages of bone augmentation (morbidity at the donor site, increased complication risks, increased time and costs, resorption of bone graft etc.) together with the increasing performance of reduced size implants should be kept in mind when developing the treatment plan [23-25]. Also, when the ridge is narrow in its coronal part, it is advised to reduce the bone height and insert shorter implants with an increased diameter than longer, narrow implants [26].

The use of cantilevers and their advantages and disadvantages must be discussed during the establishment of the treatment plan. They are more frequently encountered in overdentures, but their usage in fixed restorations must not be overlooked. Increasing the length of the cantilever has a serious influence on the maximum stress (exponential growth). For instance, a $5.5 \mathrm{~mm}$ cantilever, generates a maximum stress of $130 \mathrm{MPa}$, while a $18.5 \mathrm{~mm}$ cantilever, with the same design and material, generates $800 \mathrm{MPa}$ [27]. This does not mean that cantilevers are not recommended. On the contrary, several studies present their advantages [28-30] but restate the importance of understanding and respecting the biomechanical implications. The length of the cantilever and its potential harmful effects is also dependent on the number of implants. More splinted implants that support a prosthetic restoration presenting cantilevers reduce its negative effects and also allows for an increased length [31,32]. In fixed partial dentures that present cantilevers (mesially or distally), it is advised to use screw retention mechanisms in comparison with cement retained crowns. This seems to decrease peri implant bone stress, according to FEA [33]. Increasing the length of the implant that is closest to the cantilever and even tilting it appears to significantly reduce stress levels in peri-implant bone $[34,35]$.

The crown to implant ratio (CIR) was always seen as a key factor for success. While in natural teeth the optimal ratio is 1 (crown) to 2 (root), such ratios are almost never found in implant supported restorations due to the frequently encountered ridge atrophy. A 1:1 CIR was considered favorable and a ratio of 2:1 was considered at the limit of acceptance. This was due to the increase in alveolar ridge stress caused by the increase of momentum. Recent studies seem to only partially agree with this theory. A 5-year longitudinal cohort study published in 2019 [36] states that higher CIR values do not necessarily induce peri-implant bone loss and that using short implants may always be considered as an option in reduced bone heights. Other studies also state that increasing the CIR does not have significant effect on marginal bone loss [37-40]. Yet, some authors claim that keeping this ratio under 1.7 is mandatory to avoid complications [41] while others state that the most of the issues are encountered only when an high CIR is associated with implant tilting or cantilevers $[42,43]$. FEA suggests that the differences in maximum stress both in the surrounding bone and implant components when increasing the CIR is significant (an approximate $50 \%$ increase between $1: 1$ and $1: 1.5)$ [44,45]. All these contradictory results lead to the idea that in vitro tests (classical or computer simulations) cannot reproduce the exact in vivo conditions which seem to be more favorable to the implant's functionality. 


\section{Conclusions}

The biomechanics principles involved in oral implantology are as important as the clinical aspects. Not understanding or applying any of them will lead to certain failure. Biomechanics are involved in the conception of a new implant prototype (determining the need for certain modifications to existing designs), producing and testing (in vitro and in vivo) of the implant and all the clinical stages (planning, insertion, loading, maintenance).

Although present implants are versatile, present high success rates, increased patient acceptance and comfort, there is still room for improvement and research should go on in this field, keeping in mind all the results obtained so far.

There is no optimal solution for every patient but we can definitely talk about the optimal solution for each patient.

\section{References}

1. Brånemark PI. Osseointegration and its experimental background. J Prosthet Dent. 1983;50:399-410.

2. Abraham CM. A brief historical perspective on dental implants, their surface coatings and treatments. Open Dent J. 2014;8:50-55.

3. Duyck J, Naert IE, Van Oosterwyck H, Van der Sloten J, De Cooman M, Lievens S, et al. biomechanics of oral implants: a review of the literature. Technol Health Care. 1997;5:253273.

4. Brunski JB. Biomaterial and biomechanics in dental implant design. Int J Oral Maxillofac Implants. 1988;3:85-97.

5. Lo J, Abduo J, Palamera J. Effect of different lateral occlusion schemes on peri-implant strain: A laboratory study. J Adv Prosthodont. 2017;9:45-51.

6. Shemtov-Yona K, Rittel D. Fatigue of Dental Implants: Facts and Fallacies. Dent J (Basel). 2016;4. doi: 10.3390/ dj4020016.

7. Wiest W, Rack A, Zabler S, Schaer A, Swain M, Nelson K. Validation of finite-element simulations with synchrotron radiography - A descriptive study of micromechanics in twopiece dental implants. Heliyon. 2018;4:e00524.

8. Sugiura T, Yamamoto K, Horita S, Murakami K, Tsutsumi S, Kirita T. Effects of implant tilting and the loading direction on the displacement and micromotion of immediately loaded implants: an in vitro experiment and finite element analysis. J Periodontal Implant Sci. 2017;47:251-262.

9. Shemtov-Yona K, Rittel D. An Overview of the Mechanical Integrity of Dental Implants. Biomed Res Int. 2015;2015:547384.

10. Pjetursson BE, Thoma D, Jung R, Zwahlen M, Zembic A. A systematic review of the survival and complication rates of implant-supported fixed dental prostheses (FDPs) after a mean observation period of at least 5 years. Clin Oral Implants Res. 2012;23 Suppl 6:22-38.

11. Gupta S, Gupta H, Tandan A. Technical complications of implant-causes and management: A comprehensive review.
Natl J Maxillofac Surg. 2015;6:3-8.

12. Baggi L, Di Girolamo M, Vairo G, Sannino G. Comparative evaluation of osseointegrated dental implants based on platform-switching concept: influence of diameter, length, thread shape, and in-bone positioning depth on stress-based performance. Comput Math Methods Med. 2013;2013:250929.

13. Smeets R, Stadlinger B, Schwarz F, Beck-Broichsitter B, Jung O, Precht C, et al. Impact of Dental Implant Surface Modifications on Osseointegration. Biomed Res Int. 2016;2016:6285620.

14. Saad M, Assaf A, Gerges E. The Use of Narrow Diameter Implants in the Molar Area. Int J Dent. 2016;2016:8253090.

15. Alrabiah M. Comparison of survival rate and crestal bone loss of narrow diameter dental implants versus regular dental implants: A systematic review and meta-analysis. J Investig Clin Dent. 2019;10:e12367.

16. Schiegnitz E, Al-Nawas B. Narrow-diameter implants: A systematic review and meta-analysis. Clin Oral Implants Res. 2018;29 Suppl 16:21-40.

17. Pommer B, Mailath-Pokorny G, Haas R, Buseniechner D, Millesi W, Fürhauser R. Extra-short $(<7 \mathrm{~mm})$ and extranarrow diameter $(<3.5 \mathrm{~mm})$ implants: a meta-analytic literature review. Eur J Oral Implantol. 2018;11 Suppl 1:S137-S146.

18. Raaj G, Manimaran P, Kumar CD, Sadan DS, Abirami M. Comparative Evaluation of Implant Designs: Influence of Diameter, Length, and Taper on Stress and Strain in the Mandibular Segment-A Three-Dimensional Finite Element Analysis. J Pharm Bioallied Sci. 2019;11(Suppl 2):S347-S354.

19. Fayaz A, Geramy A, Memari Y, Rahmani Z. Effects of Length and Inclination of Implants on Terminal Abutment Teeth and Implants in Mandibular CL1 Removable Partial Denture Assessed by Three-Dimensional Finite Element Analysis. J Dent (Tehran). 2015;12:739-746.

20. Coelho Goiato MC, Pesqueira AA, Santos DM, Haddad MF, Moreno A. Photoelastic stress analysis in prosthetic implants of different diameters: mini, narrow, standard or wide. J Clin Diagn Res. 2014;8:ZC86-ZC90.

21. Gehrke SA, Frugis VL, Shibli JA, Fernandez MP, Sánchez de Val JE, Girardo JL, et al. Influence of Implant Design (Cylindrical and Conical) in the Load Transfer Surrounding Long $(13 \mathrm{~mm})$ and Short $(7 \mathrm{~mm})$ Length Implants: A Photoelastic Analysis. Open Dent J. 2016;10:522-530.

22. Lemos CAA, Verri FR, Santiago Junior JF, de Souza Batista VE, Kemmoku DT, Noritomi PY, et al. Splinted and Nonsplinted Crowns with Different Implant Lengths in the Posterior Maxilla by Three-Dimensional Finite Element Analysis. J Healthc Eng. 2018;2018:3163096.

23. de N Dias FJ, Pecorari VGA, Martins CB, Del Fabbro M, Casati MZ. Short implants versus bone augmentation in combination with standard-length implants in posterior atrophic partially edentulous mandibles: systematic review and meta-analysis with the Bayesian approach. Int J Oral Maxillofac Surg. 2019;48:90-96.

24. Palacios JAV, Garcia JJ, Caramês JMM, Quirynen M, da Silva Marques DN. Short implants versus bone grafting and 
standard-length implants placement: a systematic review. Clin Oral Investig. 2018;22:69-80.

25. Pieri F, Forlivesi C, Caselli E, Corinaldesi G. Short implants $(6 \mathrm{~mm})$ vs. vertical bone augmentation and standardlength implants $(\geq 9 \mathrm{~mm})$ in atrophic posterior mandibles: a 5-year retrospective study. Int J Oral Maxillofac Surg. 2017;46:1607-1614.

26. Jafarian M, Mirhashemi FS, Emadi N. Finite element analysis of stress distribution around a dental implant with different amounts of bone loss: An in vitro study. Dent Med Probl. 2019;56:27-32.

27. Cicciù M, Cervino G, Milone D, Risitano G. FEM Investigation of the Stress Distribution over Mandibular Bone Due to Screwed Overdenture Positioned on Dental Implants. Materials (Basel). 2018;11. doi: 10.3390/ma11091512.

28. Storelli S, Del Fabbro M, Scanferla M, Palandrani G, Romeo E. Implant-supported cantilevered fixed dental rehabilitations in fully edentulous patients: Systematic review of the literature. Part II. Clin Oral Implants Res. 2018;29 Suppl 18:275-294.

29. Storelli S, Del Fabbro M, Scanferla M, Palandrani G, Romeo E. Implant supported cantilevered fixed dental rehabilitations in partially edentulous patients: Systematic review of the literature. Part I. Clin Oral Implants Res. 2018;29 Suppl 18:253-274.

30. Freitas da Silva EV, Dos Santos DM, Sonego MV, de Luna Gomes JM, Pellizzer EP, Goiato MC. Does the Presence of a Cantilever Influence the Survival and Success of Partial Implant-Supported Dental Prostheses? Systematic Review and Meta-Analysis. Int J Oral Maxillofac Implants. 2018;33:815-823.

31. de Souza Batista VE, Verri FR, Almeida DA, Santiago Junior JF, Lemos CA, Pellizzer EP. Finite element analysis of implant-supported prosthesis with pontic and cantilever in the posterior maxilla. Comput Methods Biomech Biomed Engin. 2017;20:663-670.

32. Van Nimwegen WG, Raghoebar GM, Tymstra N, Vissink A, Meijer HJA. How to treat two adjacent missing teeth with dental implants. A systematic review on single implantsupported two-unit cantilever FDP's and results of a 5-year prospective comparative study in the aesthetic zone. J Oral Rehabil. 2017;44:461-471.

33. Alencar SM, Nogueira LB, Leal de Moura W, Rubo JH, Saymo de Oliveira Silva T, Martins GA, et al. FEA of PeriImplant Stresses in Fixed Partial Denture Prostheses with Cantilevers. J Prosthodont. 2017;26:150-155.

34. Ozan O, Kurtulmus-Yilmaz S. Biomechanical Comparison of Different Implant Inclinations and Cantilever Lengths in All-on-4 Treatment Concept by Three-Dimensional Finite Element Analysis. Int J Oral Maxillofac Implants. 2018;33:64-71.

35. Gastaldo JF, Pimentel AC, Gomes MH, Sendyk WR, Laganá
DC. Stress Analysis on Single Cobalt/Chrome Prosthesis With a 15-mm Cantilever Placed Over 10/13/15-mm-length Implants: A Simulated Photoelastic Model Study. J Oral Implantol. 2015;41:706-711.

36. Ramaglia L, Di Spirito F, Sirignano M, La Rocca M, Esposito U, Sbordone L. A 5-year longitudinal cohort study on crown to implant ratio effect on marginal bone level in single implants. Clin Implant Dent Relat Res. 2019 Mar 25. doi: 10.1111/cid.12757. [Epub ahead of print]

37. Ravidà A, Barootchi S, Alkanderi A, Tavelli L, SuárezLópez Del Amo F. The Effect of Crown-to-Implant Ratio on the Clinical Outcomes of Dental Implants: A Systematic Review. Int J Oral Maxillofac Implants. 2019 Feb 19. doi: 10.11607/jomi.7355. [Epub ahead of print]

38. Di Fiore A, Vigolo P, Sivolella S, Cavallin F, Katsoulis J, Monaco $\mathrm{C}$, et al. Influence of Crown-to-Implant Ratio on Long-Term Marginal Bone Loss Around Short Implants. Int J Oral Maxillofac Implants. 2019 Feb 19. doi: 10.11607/ jomi.7161. [Epub ahead of print]

39. Meijer HJA, Boven C, Delli K, Raghoebar GM. Is there an effect of crown-to-implant ratio on implant treatment outcomes? A systematic review. Clin Oral Implants Res. 2018;29 Suppl 18:243-252.

40. Malchiodi L, Giacomazzi E, Cucchi A, Ricciotti G, Caricasulo R, Bertossi D, et al. Relationship Between Crestal Bone Levels and Crown-to-Implant Ratio of UltraShort Implants With a Microrough Surface: A Prospective Study With 48 Months of Follow-Up. J Oral Implantol. 2019;45:18-28.

41. Hingsammer L, Watzek G, Pommer B. The influence of crown-to-implant ratio on marginal bone levels around splinted short dental implants: A radiological and clincial short term analysis. Clin Implant Dent Relat Res. 2017;19:1090-1098.

42. Sotto-Maior BS, Senna PM, da Silva-Neto JP, de Arruda Nóbilo MA, Del Bel Cury AA. Influence of crown-toimplant ratio on stress around single short-wide implants: a photoelastic stress analysis. J Prosthodont. 2015;24:52-56.

43. Anitua E, Piñas L, Orive G. Retrospective study of short and extra-short implants placed in posterior regions: influence of crown-to-implant ratio on marginal bone loss. Clin Implant Dent Relat Res. 2015;17:102-110.

44. Verri FR, Batista VE, Santiago JF Jr, Almeida DA, Pellizzer EP. Effect of crown-to-implant ratio on peri-implant stress: a finite element analysis. Mater Sci Eng C Mater Biol Appl. 2014;45:234-240.

45. Ramos Verri F, Santiago Junior JF, de Faria Almeida DA, de Oliveira GB, de Souza Batista VE, Marques Honório H, et al. Biomechanical influence of crown-to-implant ratio on stress distribution over internal hexagon short implant: 3-D finite element analysis with statistical test. J Biomech. 2015;48:138-145. 